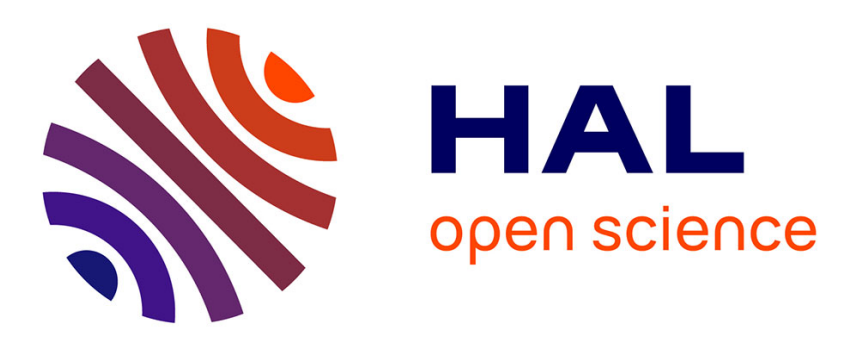

\title{
Ultra-violet optical amplifier based on plasma-core PCF
} Frédéric Delahaye, Foued Amrani, Benoît Debord, Frédéric Gérôme, Fetah

\author{
Benabid
}

\section{To cite this version:}

Frédéric Delahaye, Foued Amrani, Benoît Debord, Frédéric Gérôme, Fetah Benabid. Ultra-violet optical amplifier based on plasma-core PCF. Conference on Laser and Electro-Optics /Europe (CLEO/Europe-EQEC 2019), Jun 2019, OSA, Jun 2019, Munich, Germany. Paper CJ-3.1. hal02330742

\section{HAL Id: hal-02330742 \\ https://hal.science/hal-02330742}

Submitted on 23 Nov 2020

HAL is a multi-disciplinary open access archive for the deposit and dissemination of scientific research documents, whether they are published or not. The documents may come from teaching and research institutions in France or abroad, or from public or private research centers.
L'archive ouverte pluridisciplinaire HAL, est destinée au dépôt et à la diffusion de documents scientifiques de niveau recherche, publiés ou non, émanant des établissements d'enseignement et de recherche français ou étrangers, des laboratoires publics ou privés. 


\title{
Ultra-violet optical amplifier based on plasma-core PCF
}

\author{
Frédéric Delahaye $^{1}$, Foued Amrani $^{1}$, Benoît Debord ${ }^{1}$, Frédéric Gérôme ${ }^{1}$ and Fetah Benabid $^{1}$ \\ 1. GPPMM group, University of Limoges, CNRS, XLIM, UMR 7252, F-87000 Limoges, France
}

Optical amplifiers are an important key element in modern physics. For example, in optical communication, in order to transmit signal over long distance, they are inserted to compensate optical signal attenuation due to fiber loss. For system laser they are used as active gain medium. Today, optical amplifiers can be divided into two classes: doped fiber and solid-state amplifiers [1]. However, these conventional amplifiers are mainly limited to the visible and near infrared spectral range. This limitation is particularly acute in the ultra-violet (UV) range because of the lack of suitable materials for UV emission and optical guidance. Conversely, gas-filled hollow-core photonic crystal fiber (HCPCF) has successfully been extended to ionized gases by generating and micro-confining stable plasma using non-intrusive [2] and compact microwave surface-wave excitation configuration [3]. It was proven that with this new plasma-core PCF (PCPCF), one could emit radiation over a large spectrum including several lines in the UV and DUV [4].

In this paper, we report to our knowledge on the first DUV/UV amplifier using an "all plasma-core PCF" architecture whereby radiation line at $315 \mathrm{~nm}$ was generated in one PCPCF and amplified with a maximum gain of $\sim 14 \mathrm{~dB}$ by a second PCPCF for a microwave pump of $17 \mathrm{~W}$.

Fig.1 (a) shows the two stages experimental set-up. The first stage consists of a PCPCF used to generate the signal. The latter is filtered from the plasma radiation spectrum by a diffractive grating before sending to the second stage of the set-up comprised with a second PCPCF. Both PCPCF are excited with a microwave generator (the details of this technique is detailed in [2]). The two PCPCF are made with a $20 \mathrm{~cm}$ long 19-cell hollow-core defect Kagome PCF filled with a ternary gas mixture of argon, nitrogen and oxygen $\left(\mathrm{Ar} / \mathrm{N}_{2} / \mathrm{O}_{2}\right)$. Fig. 1(b-1) shows the typical emitted spectrum in the range of $250-425 \mathrm{~nm}$ when the above PCPCF is excited with $17 \mathrm{~W}$ microwave power. Fig. 1(b-2) and 1(b-3) summarizes the evolution of the spectrum emitted from the amplifying PCPCF when a radiation line at $315 \mathrm{~nm}$ of $35 \mathrm{nW}$ from the first PCPCF is coupled in. The grey-filled curves represent the spectrum in the absence of $315 \mathrm{~nm}$ seed line, and the blue-curves represent the spectrum with the presence of the seed for two values of the amplifying PCPCF microwave excitation power. For a microwave power of $15 \mathrm{~W}$, we readily see a strong amplification of the $315 \mathrm{~nm}$ line and suppression of the rest of spectrum lines. The gain evolve with the amplifying PCPCF microwave excitation power for a seed line at $315 \mathrm{~nm}$. By gradually increasing the microwave power, the gain increases linearly with the microwave power indicating that the population inversion is sufficient to provide gain. Within this microwave range the gain increases almost linearly to a maximum of $\sim 14$ $\mathrm{dB}$. Current effort is to increase the microwave power to determine the saturation level.

In conclusion, a new type of DUV/UV optical amplifier is proposed. An experimental demonstration of $\sim 14$ $\mathrm{dB}$ amplification of radiations at $315 \mathrm{~nm}$ is achieved. The results indicate that the PCPCF technology is an excellent candidate for reproducing the outstanding results of near infrared lasers in the "untamed" DUV/UV spectral range.
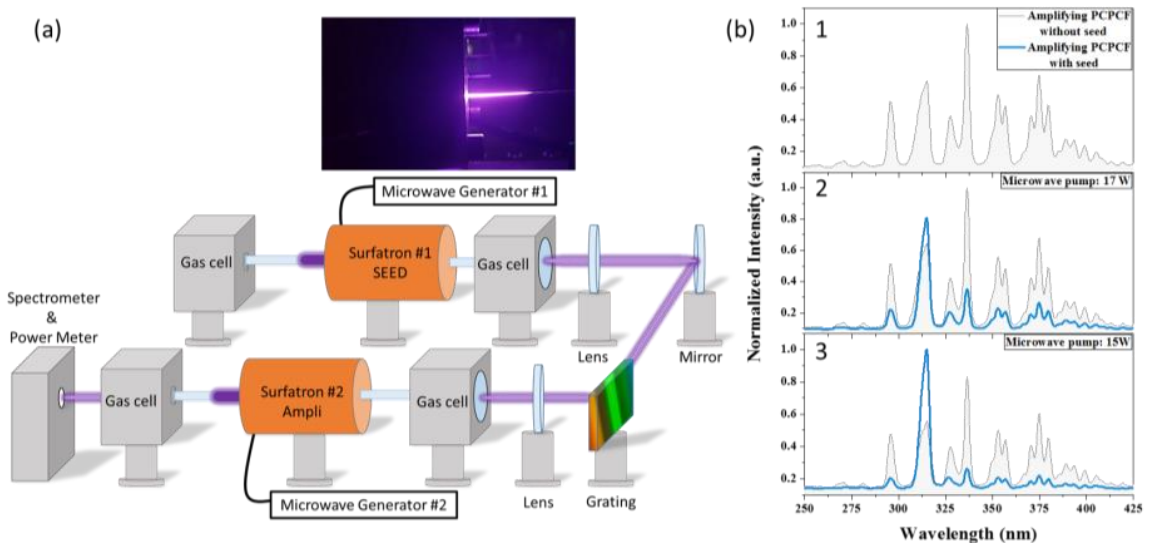

Fig. 1 (a) Experimental set-up. (b) Emitted DUV/UV spectra from the amplifying PCPCF in the case of no seed line (grey filled curves), and in the presence of $35 \mathrm{nW} 315 \mathrm{~nm}$ seed line (blue curves) for the case of 17 W (Fig. 1(b-2)) and $15 \mathrm{~W}$ (Fig. 1(b-3)) of microwave excitation power.

This research is funded through grants ANR-DGA Maturation Plasma-PMC, PIA-4F and la région Nouvelle Aquitaine.

[1] D. Zimmermann et al., "Amplifiers for the masses: EDFA, EDWA, and SOA amplets for metro and access applications", Journal of Lightwave Technology, 2004

[2] B. Debord et al., "Generation and confinement of microwave gas-plasma in photonic dielectric microstructure", Optic Express, 2013

[3] F. Vial et al., "Generation of surface-wave microwave microplasmas in hollow-core photonic crystal fiber based on a split-ring resonator" Optics Letters, 2016

[4] F. Amrani et al., "Gas mixture for deep-UV plasma emission in a hollow-core photonic crystal fiber", Optics Letters, 2017 